\title{
Implantação do Efficient Consumer Response (ECR): um Estudo Multicaso com Indústrias, Atacadistas e Varejistas
}

\author{
FláviaAngeli Ghisi \\ Andrea Lago da Silva
}

\begin{abstract}
RESUMO
Introduzido na década de 90 nos Estados Unidos, o Efficient Consumer Response (ECR) teve sua maior difusão no Brasil em 1997, ano em que foi criada a Associação ECR Brasil, que passou a coordenar diversos projetos-piloto de ECR. Embora exista um esforço crescente das empresas em divulgar os fundamentos do ECR e o crescente interesse acadêmico por esse tema, é perceptível a dificuldade na compreensão da sua implementação e operacionalização. Com base nesse fato, o objetivo desse trabalho é fazer uma análise crítica da implementação do ECR, com base em pesquisa qualitativa realizada com indústrias, atacadistas e varejistas que compõem o canal de distribuição de produtos de mercearia básica. Buscou-se identificar nessa pesquisa que estratégias, processos e tecnologias do ECR estavam sendo realmente empregadas pelas empresas, os motivos que levaram essas organizações a implementá-las, as dificuldades enfrentadas nesse processo e a visão das empresas pesquisadas quanto a seus desdobramentos futuros no Brasil. Os resultados dessa pesquisa podem contribuir àquelas empresas que pretendem maximizar a implementação do ECR ou iniciar o processo de adoção dessa estratégia de gestão.
\end{abstract}

Palavras-chave: ECR; canais de distribuição; colaboração.

\begin{abstract}
Introduced in the 1990s, the Efficient Consumer Response (ECR) sought to fill this void by focusing on improving inter-organizational efficiency in firms. The basic outline of the ECR initiative was first presented in the United States and its diffusion to Brazil occurred in 1997, when the Brazilian ECR Association was created and began to develop many ECR projects. Although ECR been one of most important subjects discussed by the grocery industry, the lack of publications regarding its outcomes is notable. As a result, there is a need to develop new studies about the impact of ECR on the grocery supply chain. Based on these facts, the objective of this study is to discuss the concept of ECR and its development, by critically analyzing ECR implementation and discussing it perspective. The study is supported by a field research conducted with industries, wholesalers and retailers of the grocery industry channel in Brazil. This research attempted to identify which strategies, processes and technologies of ECR were been applied by these companies, the reasons of those firms adoption the ECR, the difficulties confronted in this process and the opinions of them about the ECR diffusion in Brazil. The results can provides useful insights to companies that want to implement ECR strategies or need to improve it implementation.
\end{abstract}

Key words: ECR; grocery industry; supply chain. 


\section{INTRODUÇÃO}

A maior estabilidade da moeda brasileira, após o estabelecimento do Plano Real na década de 90, juntamente com a abertura do comércio ao mercado externo resultaram em reflexos positivos nas vendas de produtos industrializados de consumo e no comércio em geral. Surge nesse período um consumidor mais atento aos preços praticados, mas também mais exigente por serviços diferenciados, demandando produtos de qualidade. Isto de certa forma exigiu um reposicionamento competitivo por parte dos membros do canal de distribuição de produtos de mercearia básica (alimentos, higiene, beleza e limpeza), acostumados, durante décadas, a comportamentos desleais (Alcântara, 1999; Fleury, Wanke, \& Figueiredo, 2000; Silveira \& Lepsch, 1997). Na maioria das transações realizadas nesse período, o vendedor buscava negociar a maior quantidade de produtos ao preço mais elevado possível, para conseguir fornecer algum desconto promocional em seguida. Com isso, ele conseguia maximizar a venda de mercadorias. Os compradores, por outro lado, buscavam altas margens de lucros. Nos períodos que encontravam bons descontos, eles acabavam comprando uma quantidade adicional de produtos para armazenagem e, posteriormente, tentavam revendê-los a um valor mais elevado no mercado (Harris \& Swatman, 1997).

Logo, os fornecedores, principalmente as indústrias, começaram a perceber que os descontos concedidos não estavam sendo repassados para os consumidores finais. Na verdade, esses fornecedores estavam subsidiando as operações de negócios dos varejistas e atacadistas (Kurt Salmon Associates [KSA], 1993). Entretanto, enquanto as margens de lucro permaneciam elevadas, os varejistas toleravam as ineficiências, mesmo com o aumento dos custos administrativos, transporte e de estocagem, estimulados pela estratégia de descontos dos fornecedores (Harris \& Swatman, 1997). No final da década de 80 e início de 90 , as empresas participantes do canal de distribuição de produtos de mercearia básica começaram a sentir a perda de competitividade e eficiência. (Fox, 1992; Garry, 1992, 1994; O’Neill, 1992). Muitos varejistas sofreram uma compressão em suas margens de lucro devido ao aumento da competição e ao interesse do consumidor por preços baixos. As empresas foram então pressionadas à intensificar o controle dos custos internos e melhorar o serviço oferecido ao consumidor final (Fleury et al., 2000). 
Tendo em vista tais mudanças, novas ferramentas para auxiliar a gestão do canal de distribuição surgiram nesse período. Dentre elas, uma das que mais receberam destaque no setor de mercearia básica foi o Efficient Consumer Response (ECR), em português, Resposta Eficiente ao Consumidor. As práticas do ECR, fundamentadas em quatro estratégias de negócios, visam à melhoria da eficiência do canal através da simplificação, padronização e racionalização dos processos, assim como a redução de custos e a troca de informações entre varejistas e seus fornecedores (Rojo, 1998; Silva, 1999).

No âmbito acadêmico, a importância deste trabalho se justifica pelo fato de poucos estudos terem sido realizados sobre o ECR, mesmo considerando a relevância desse tema para as indústrias, atacadistas e varejistas. A carência de livros, artigos, dissertações e teses sobre o tema, a representatividade e importância do assunto e do setor e ainda a necessidade de maior profundidade das publicações reforçam a necessidade de que novos estudos relacionados ao ECR sejam iniciados.

Em termos práticos, embora exista grande carência de publicações acadêmicas sobre o ECR, ele é um dos principais assuntos abordados nas reuniões e eventos da indústria supermercadista. Nesse sentido, o estudo contribui ao fazer recomendações sobre como melhorar o processo de adoção do ECR pelas empresas, para que seja possível melhorar a eficiência do canal de distribuição de produtos de mercearia básica.

Este trabalho buscou proporcionar melhor compreensão do surgimento e disseminação do ECR, sua finalidade, operacionalização e implementação. Pretende-se aqui fazer um levantamento qualitativo e crítico do atual nível de implementação do ECR, através da identificação do que realmente está sendo empregado nas empresas no que tange a essa estratégia de gestão, os motivos que levaram essas organizações a implementá-la, as dificuldades enfrentadas e os ganhos percebidos.

\section{ECR}

\section{Perspectiva Histórica do ECR}

No final da década de 80 e início de 90, as organizações do canal de distribuição de produtos de mercearia básica começaram a sentir a perda de competitividade 
e eficiência, quando comparadas com outros canais; o resultado foi a queda nas suas vendas (Fox, 1992; Garry, 1992, 1994; O’Neill 1992). Outros fatores contribuíram nesse processo, tais como: redução das taxas de natalidade, tempo disponível para o preparo das refeições em casa, fortalecimento no final da década de 80 e início dos anos 90 das redes de fast-food e a intensificação competitiva no setor, derivada, principalmente, do aparecimento de formatos alternativos de varejo (como os clubes atacadistas, lojas de descontos etc.) (Dib, 1997; Garry, 1995; Kurnia, Swatman, \& Schauder, 1998; Newton, 1993; Whipple, Frankel, \& Anselmi, 1999).

Um estudo conduzido pela McKinsey para o Food Marketing Institute (FMI), em 1991, mostrou que esses novos formatos de varejo tinham preços mais competitivos do que os varejistas tradicionais (KSA, 1993). Como consequiência da redução das margens de lucro, as relações entre os parceiros comerciais tornaram-se ainda mais críticas, sendo difíceis os acordos de interesse de ambas as partes. Nos anos 90, estas ineficiências motivaram os varejistas e as indústrias a buscarem formas alternativas para reduzir o nível elevado do inventário no canal de distribuição (Clark \& Croson, 1997). A partir dos trabalhos realizados por uma força-tarefa composta por líderes da indústria de alimentos e do setor de distribuição americano e algumas associações comerciais financiadoras (KSA, 1993; Poirier \& Reiter, 1996; Sansolo, 1993), a Kurt Salmon Associates (KSA), levantaram-se oportunidades para o aperfeiçoamento, reengenharia recomendada e redesenho do canal de distribuição, a partir do fabricante até a venda no varejo. O resultado desse esforço foi a publicação do Efficient Consumer Response: Enhancing Consumer Value in the Grocery Industry, primeiro documento do ECR que se tornou referência para os diversos pesquisadores do tema (KSA, 1993).

\section{Definição e Conceitos Básicos do ECR}

Existem diversas definições para o termo ECR. Na teoria estudada o ECR foi tratado, por diferentes autores, como sendo uma inovação gerencial: estratégia de gestão ou de negócio, processo, ferramenta, prática ou filosofia de gestão. Buscou-se, aqui, relatar alguns conceitos com base na visão de diferentes autores selecionados, em ordem cronológica, desde o seu surgimento (Quadro 1). 


\section{Quadro 1: Definição do ECR na Visão de Autores Selecionados em Ordem Cronológica}

\begin{tabular}{|c|c|}
\hline Autores/ano & Definição do ECR \\
\hline $\begin{array}{l}\text { Kurt Salmon Associates } \\
\text { (1993) }\end{array}$ & $\begin{array}{l}\text { O ECR é uma estratégia do canal de distribuição, na qual fornecedores, atacadistas e } \\
\text { varejistas trabalham em conjunto, visando proporcionar maior valor ao consumidor }\end{array}$ \\
\hline $\begin{array}{l}\text { De Roulet } \\
(1993)\end{array}$ & $\begin{array}{l}\text { O ECR baseia-se em um conjunto de estratégias que forçam as funções tradicionais } \\
\text { de logística, vendas e marketing a um novo alinhamento, o que possibilita otimizar } \\
\text { a eficiência da empresa e agregar valor ao consumidor }\end{array}$ \\
\hline $\begin{array}{l}\text { King, Ashman e Bosley } \\
\text { (1994) }\end{array}$ & $\begin{array}{l}\text { O ECR é uma estratégia colaborativa da indústria supermercadista para promover o } \\
\text { estabelecimento e a implementação de novas relações e novas práticas de negócios, } \\
\text { assim como a adoção de novas tecnologias pelos produtores, distribuidores e } \\
\text { varejistas }\end{array}$ \\
\hline $\begin{array}{l}\text { Pearche } \\
(1996)\end{array}$ & $\begin{array}{l}\text { O ECR é o processo que facilita o trabalho conjunto entre os parceiros comerciais, } \\
\text { visando fundamentalmente à satisfação do consumidor, maximizando, } \\
\text { conseqüientemente, a eficiência do negócio }\end{array}$ \\
\hline $\begin{array}{l}\text { Phumpiu e King } \\
\text { (1997) }\end{array}$ & $\begin{array}{l}\text { O ECR é um esforço colaborativo do canal de distribuição, para promover a } \\
\text { eficiência e a resposta para os consumidores através de novas formas de } \\
\text { coordenação e cooperação, juntamente com novas aplicações de tecnologia de } \\
\text { informação }\end{array}$ \\
\hline $\begin{array}{l}\text { Kurnia, Swatman e } \\
\text { Schauder } \\
\text { (1998) }\end{array}$ & $\begin{array}{l}\text { O ECR é uma estratégia delineada para eliminar ineficiências e custos que não } \\
\text { agregam valor ao longo da cadeia de suprimentos, para poder, assim, melhor } \\
\text { satifazer os consumidores }\end{array}$ \\
\hline $\begin{array}{l}\text { Brockman e Morgan } \\
\text { (1999) }\end{array}$ & $\begin{array}{l}\text { O ECR é a mais complexa inovação gerencial no processo de distribuição de } \\
\text { produtos, mesmo considerando o Quick Response, devido ao alto nível de confiança } \\
\text { exigida pelos parceiros comerciais para que esta estratégia tenha sucesso }\end{array}$ \\
\hline $\begin{array}{l}\text { Kotzab } \\
(1999)\end{array}$ & $\begin{array}{l}\text { O ECR é o nome que se dá para a estratégia logística baseada no sistema "just-in- } \\
\text { time" na indústria supermercadista }\end{array}$ \\
\hline $\begin{array}{l}\text { Hoffman e Mehra } \\
\qquad(2000)\end{array}$ & $\begin{array}{l}\text { O ECR é uma estratégia que estimula os participantes da cadeia de suprimentos a } \\
\text { estudar e a implementar métodos que possibilitem o trabalho conjunto entre os } \\
\text { participantes, para que juntos consigam atingir a missão da cadeia como um todo }\end{array}$ \\
\hline
\end{tabular}

Fonte: Ghisi (2001).

Com base na bibliografia estudada, buscou-se elaborar uma definição para o termo ECR: estratégia de gestão do canal de distribuição em que os fornecedores, atacadistas e varejistas trabalham de forma integrada para eliminar ineficiências e reduzir custos excessivos, com o objetivo de atender às necessidades e expectativas dos consumidores e maximizar a eficiência dos negócios para as partes envolvidas em uma negociação.

Para a adoção do ECR muitos acordos e negociações devem ser realizados, não só pelas áreas de logística de ambos os parceiros, mas também pelas áreas de informática/sistemas, comerciais e de compras. 


\section{Configuração do ECR}

O ECR engloba uma série de tecnologias, processos e métodos, e sua viabilização é verificada por meio da aplicação de quatro importantes estratégias, que lhe dão sustentação: Reposição Eficiente de Produtos, Sortimento Eficiente de Produtos, Promoção Eficiente de Produtos e Introdução Eficiente de Produtos. A definição dessas estratégias, bem como os seus principais pontos relevantes estão descritos no Quadro 2.

\section{Quadro 2: As Estratégias do ECR, Definições e Principais Aspectos}

\begin{tabular}{|c|c|c|}
\hline Estratégias do ECR & Definições & Principais Aspectos \\
\hline $\begin{array}{l}\text { Reposição Eficiente de } \\
\text { Produtos }\end{array}$ & $\begin{array}{l}\text { Redução de tempo e custos na } \\
\text { reposição de produtos: repor o } \\
\text { produto certo, no local certo, na } \\
\text { hora certa, da maneira mais } \\
\text { eficiente possível }\end{array}$ & $\begin{array}{l}\text { - pedidos automatizados } \\
\text { - intercâmbio de informações (EDI) } \\
\text { - ligação de todo o canal em um único fluxo, } \\
\text { desde a produção até o ponto de venda do } \\
\text { varejista } \\
\text { - estima-se a redução em } 4,1 \% \text { nos preços finais } \\
\text { dos produtos com a adoção dessa estratégia }\end{array}$ \\
\hline $\begin{array}{l}\text { Sortimento Eficiente de } \\
\text { Produtos }\end{array}$ & $\begin{array}{l}\text { Melhoria no mix de produtos e } \\
\text { gerenciamento dos níveis de } \\
\text { estoque nas lojas: melhor } \\
\text { gerenciamento dos estoques e } \\
\text { espaços da loja na interface com o } \\
\text { consumidor }\end{array}$ & $\begin{array}{l}\text { - melhor utilização do espaço em loja } \\
\text { - aumento do giro de estoque } \\
\text { - definição da categoria de produtos de acordo } \\
\text { com o comportamento de compras dos } \\
\text { consumidores } \\
\text { - estima-se a redução em } 1,5 \% \text { nos preços finais } \\
\text { dos produtos com a adoção dessa estratégia }\end{array}$ \\
\hline $\begin{array}{l}\text { Promoção Eficiente de } \\
\text { Produtos }\end{array}$ & $\begin{array}{l}\text { Melhor planejamento } \mathrm{e} \\
\text { gerenciamento das promoções: } \\
\text { melhorar a alocação dos recursos } \\
\text { direcionados à promoção }\end{array}$ & $\begin{array}{l}\text { - desconto contínuo estabelecidos entre ambas as } \\
\text { partes de uma negociação } \\
\text { - compartilhamento dos ganhos com as } \\
\text { promoções entre os elos do canal } \\
\text { - estima-se a redução em } 4,3 \% \text { nos preços finais } \\
\text { dos produtos com a adoção dessa estratégia }\end{array}$ \\
\hline $\begin{array}{l}\text { Introdução Eficiente de } \\
\text { Produtos }\end{array}$ & $\begin{array}{l}\text { Melhoria no desenvolvimento e } \\
\text { introdução de novos produtos: } \\
\text { identificar oportunidades de } \\
\text { mercado com base na visão do } \\
\text { cliente final }\end{array}$ & $\begin{array}{l}\text { - redução da taxa de insucesso dos novos } \\
\text { produtos introduzidos, melhorando a } \\
\text { performance destes } \\
\text { - identificação de oportunidades de mercado com } \\
\text { base na visão do cliente } \\
\text { - estima-se a redução em } 0,9 \% \text { nos preços finais } \\
\text { dos produtos com a adoção dessa estratégia }\end{array}$ \\
\hline
\end{tabular}

Fonte: elaborado pela autora a partir das informações de Kurt Salmon Associates (1993); Sansolo (1993); De Roulet (1993); Clark e Croson (1997); Dib (1997) e ECR Brasil (1998).

Essas estratégias contam com o apoio de dois processos-chave: gerenciamento por categorias e reposição contínua de produtos, assim como com o suporte de diversas tecnologias e métodos: códigos de barras/scanners, troca eletrônica de dados, pedido ordenado por computador, cross docking, entrega direta em loja e custeio baseado em atividades. Estas tecnologias e métodos fornecem a estrutura para a adoção dos processos que são fundamentais para a concretização das 
estratégias do ECR. O conjunto das estratégias, processos, tecnologias e métodos, formam a configuração do ECR (Figura 1). Para a operacionalização da estratégia Reposição Eficiente de Produtos, os processos de reposição contínua e gerenciamento por categorias tornam-se vitais. Eles contam ainda com o suporte técnico do código de barras/scanner, EDI, cross-docking, entrega direta em loja, pedido ordenado por computador e o método ABC. Para o funcionamento das estratégias Sortimento Eficiente de Produtos, Promoção Eficiente de Produtos e Introdução Eficiente de Produtos, o processo-chave é o gerenciamento por categorias, que é suportado pelo código de barras/scanners, EDI e ABC.

Figura 1: Configuração do ECR

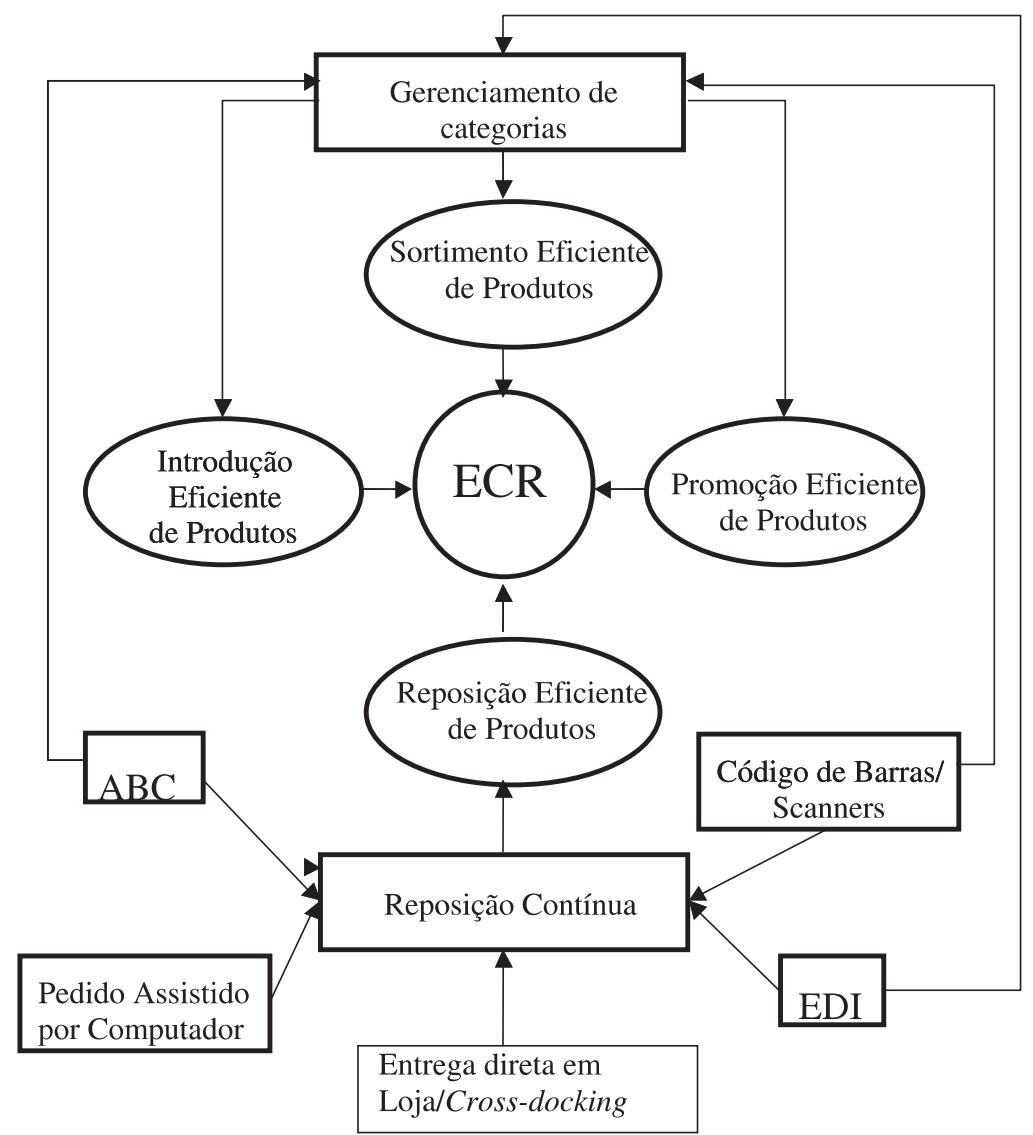

Fonte: adaptada de Kurnia et al.(1998). 


\section{Implantação das Práticas de ECR: Benefícios e Dificuldades}

Os resultados da aplicação das estratégias do ECR mostram a existência de benefícios para todos os agentes primários do canal de distribuição, listados no Quadro 3.

\section{Quadro 3: Benefícios do ECR para os Agentes do Canal de Distribuição}

\begin{tabular}{|c|c|}
\hline Consumidores & $\begin{array}{l}\text { - maior sortimento de produtos e maior conveniência } \\
\text { - } \text { facilidade em encontrar todos os produtos que deseja } \\
\text { - } \quad \text { produtos mais frescos e de melhor qualidade } \\
\text { - } \quad \text { produtos a preços mais justos e serviços mais eficientes }\end{array}$ \\
\hline Varejistas & $\begin{array}{l}\text { - } \text { consumidores mais leais } \\
\text { - } \quad \text { redução mix de produtos níveis de estoque e itens em falta } \\
\text { - } \text { melhor conhecimento do consumidor } \\
\text { - } \text { redução do tempo de reabastecimento } \\
\text { - } \text { aumento das vendas } \\
\text { - } \text { melhor relacionamento com o fornecedor } \\
\text { - redução dos custos operacionais e administrativos } \\
\text { - redução dos custos de transação } \\
\text { - } \quad \text { redução do tempo de recebimento de mercadorias }\end{array}$ \\
\hline Atacadistas e Indústrias & $\begin{array}{l}\text { - } \text { redução dos níveis de estoque } \\
\text { - } \text { melhor conhecimento do consumidor } \\
\text { - } \text { maior eficiência no reabastecimento de mercadorias } \\
\text { - } \quad \text { maior eficiência nos lançamentos de produtos e promoções } \\
\text { - } \text { aumento da integridade da marca } \\
\text { - } \text { melhor relacionamento com o varejista } \\
\text { - } \quad \text { redução dos custos operacionais e administrativos } \\
\text { - } \quad \text { redução dos custos de transação } \\
\end{array}$ \\
\hline
\end{tabular}

Fonte: elaborado pelas autoras a partir de Kurt Salmon Associates (1993); Dib (1997); Ross (1996); Vilallonga (1996); ECR Brasil (1998); Vantine (1998); Harris et al. (1999); Ching (1999) e Ghisi (2000).

No entanto, existem diversas dificuldades que impedem o avanço do ECR nas empresas (ECR Brasil, 1998; Ghisi, 2000; Ross, 1996; Vantine, 1998). Um dos principais problemas está associado à dificuldade de promover a mudança na cultura da empresa e na forma de gerir os negócios, isso porque os agentes do canal nem sempre estão preparados para trocar informações relevantes, abrir dados para os parceiros comerciais e ter visão de todo o processo. Outro problema identificado é o conflito de prioridades, pois nem sempre os interesses em investir no ECR são semelhantes para a indústria, atacado e varejo. Outro problema evidenciado é a inadequação da previsão de vendas, aspecto não abordado pelo ECR e elemento crítico no gerenciamento do canal de distribuição.

O comprometimento interno, não apenas da alta administração, mas também dos outros membros da organização nos projetos referentes ao ECR, também é 
uma dificuldade enfrentada. Os membros dos diversos departamentos devem estar aptos a receber e a trabalhar as novas informações, estando suscetíveis e motivados ao trabalho conjunto, propondo mudanças no negócio, que venham facilitar a introdução do ECR. O comprometimento externo também é outro obstáculo, já que a colaboração e o comprometimento dos agentes do canal assumem um papel essencial, pois para a concretização do ECR é fundamental que ambas as partes estejam comprometidas: o esforço unilateral é desgastante e insuficiente para promover mudanças substanciais (ECR Brasil, 1998).

Outra dificuldade está relacionada à gestão das informações. Para que as informações sejam tratadas, é preciso considerar a área de tecnologia de informação como unidade estratégica de negócio. Um dos grandes problemas a ser superado é a resistência interna, pois alguns funcionários, principalmente dos departamentos de compras e vendas, acreditam que adotar o ECR implica demissões de pessoal. Torna-se, então, fundamental que os gerentes dessas empresas prepararem o seu pessoal para evitar esse tipo de conflito. Os funcionários devem ser treinados e então alocados para outras funções que agreguem mais valor para o consumidor final (ECR Brasil, 1998).

A adequação da tecnologia e dos processos é outra dificuldade presenciada pelas empresas. A tecnologia interna é, algumas vezes, inadequada aos formatos tecnológicos dos fornecedores parceiros ou incapazes de fornecer informações essenciais na tomada de decisões. Isso requer investimentos em tecnologia, nem sempre disponíveis nas empresas que compõem o canal (o ECR exige constantes atualizações nas tecnologias adotadas). Para finalizar, tem-se a dificuldade em focar o consumidor. Um dos aspectos mais criticados no contexto do ECR é justamente a falta de reconhecimento, em tempo hábil, das mudanças nos hábitos de consumo. O consumidor deveria, na filosofia do ECR, ser o foco de todos os esforços das indústrias, atacadistas e varejistas.

\section{Metodologia}

Para esse estudo, foram pesquisadas quatro indústrias, dois atacadistas e dois varejistas de grande porte, altamente representativos nos setores em que atuam, considerados referências de empresas que implementaram o ECR no Brasil (com base na indicação da Associação ECR Brasil e especialistas da área). Foi solicitado também à Associação ECR Brasil uma carta de apoio à pesquisa, com o objetivo de facilitar o agendamento das entrevistas. Juntamente com essa carta, foi enviando um protocolo de pesquisa, explicando o objetivo do trabalho e a importância dos empresários em se comprometerem em participar do trabalho. Dentre as empresas potenciais a serem pesquisadas, foram selecionadas apenas 
as empresas que tinham características que contribuíssem com a investigação proposta (Selltiz \& Cook, 1974). Para a definição da amostra, consideraram-se alguns critérios-chave: varejistas e atacadistas que se encontravam entre os 10 primeiros em termos de faturamento no mercado brasileiro no ano de 2000, segundo dados das revistas SuperHiper e Distribuição, respectivamente, e que já tivessem desenvolvido projetos-piloto de ECR na empresa, há pelo menos dois anos, com base nas indicações do ECR Brasil; e indústrias de produtos de mercearia básica indicadas pelos varejistas e atacadistas pesquisados; foi solicitado aos varejistas e atacadistas que indicassem indústrias fornecedoras do setor de mercearia básica, com quem já tivessem desenvolvido projetos-piloto de ECR há pelo menos dois anos.

Considerou-se pertinente e adequado ao objetivo do trabalho optar por aquelas instituições que já tivessem iniciado esforços rumo à implementação do ECR há pelo menos dois anos e que, portanto, tinham conhecimento e experiência nesse processo. Isso implicava a escolha de empresas que já tivessem implementado projetos-piloto de ECR.

A opção pelo tipo de pesquisa a ser empreendido neste trabalho foi a qualitativa. A amostra, de caráter não-probabilístico, foi escolhida por meio de uma amostragem por conveniência. Nesta pesquisa, essa técnica era a mais apropriada, pois permitia a seleção de componentes da amostra de acordo com as características necessárias para a obtenção de casos considerados típicos nessa população. Dado que um dos objetivos dessa pesquisa era investigar com maior profundidade algumas empresas específicas que já tivessem implementado o ECR, optou-se pelo estudo de multicaso, que segundo Yin (1994), é uma pesquisa de natureza empírica, que investiga o fenômeno atual dentro da situação onde ele ocorre, sendo especialmente adequado aos estudos nos quais os limites entre o fenômeno e o contexto não são claros. O estudo multicaso trouxe relevantes revelações, permitindo aprofundar a descrição da operacionalização do ECR e identificar novos elementos ou dimensões que pudessem agregar valor ao estudo.

A coleta de dados foi feita através de entrevistas pessoais, que tiveram duração média de duas horas e meia. No entanto vale ressaltar que, pela dificuldade de acesso aos varejistas do Estado de São Paulo, um dos questionários foi enviado por e-mail e conferido por telefone. As entrevistas foram gravadas e, então, transcritas, buscando identificar semelhanças e diferenças entre os casos estudados. Houve a necessidade de retorno em algumas empresas e alguns novos contatos para a coleta de informações adicionais.

Foram entrevistados em média 3 pessoas por empresa, sendo estas as que possuíam uma visão ampla do ECR na organização e que, na grande maioria dos casos, participaram do processo de implementação dos projetos-piloto de ECR 
na empresa. $\mathrm{O}$ instrumento de coleta utilizado na pesquisa de campo foi um questionário semi-estruturado, contendo questões abertas e fechadas, aplicado a um conjunto de pessoas escolhidas em função de critérios de representatividade da população global objeto de investigação.

O questionário foi dividido em quatro seções. A primeira buscava caracterizar a empresa pesquisada. A segunda tinha o objetivo de avaliar o relacionamento da empresa com seus parceiros comerciais. A terceira seção buscava verificar o que estava sendo feito na empresa em termos das tecnologias, métodos e processos do ECR, dificuldades presenciadas, ganhos etc. A quarta e última seção focava mais especificamente as estratégias do ECR, as expectativas da empresa quanto à adoção e a difusão dessas estratégias, necessidade de mudanças estruturais e recursos para sua implementação.

Buscou-se sempre pesquisar as empresas mais evoluídas quanto à implementação do ECR, mas mesmo naquelas tidas como tais, ainda esse conceito não estava largamente difundido. Ainda assim, algumas empresas como Wal-Mart, Carrefour, Pão-de-Açúcar e Gessy Lever, consideradas referências no assunto, não concederam as entrevistas, alegando, principalmente, a necessidade de sigilo. Outros problemas também foram encontrados, tais como cancelamento de entrevistas na véspera, dificuldade em conseguir as entrevistas com os principais profissionais dos tópicos da pesquisa e dificuldade em conseguir o agendamento, já que muitas empresas estavam em fase de adequação dos sistemas internos.

Os dados foram tratados de forma consolidada, mantendo-se a confidencialidade das empresas pesquisadas. No entanto, para uma melhor compreensão dos resultados, a análise foi feita com a distinção dos varejistas, atacadistas e indústrias.

\section{Análise e Discussão dos Resultados}

\section{Implementação do ECR}

De maneira geral, a iniciativa em investir no ECR partiu da diretoria das empresas. No processo de difusão para os demais níveis hierárquicos, houve o envolvimento da área de logística, financeira, comercial, informática e sistemas. Embora se acreditasse que a área comercial seria a mais envolvida nos projetospiloto, a pesquisa de campo mostrou que as áreas logística e sistemas/informática foram as que mais se envolveram. Dada a influência tecnológica para a viabilização do ECR e a importância da logística assumida nesse contexto, as áreas de sistemas/informações e logística assumiram uma posição estratégica para as empresas. Por outro lado, com a adoção do ECR algumas empresas 
reduziram seu quadro de vendedores e alteraram as funções tradicionalmente desempenhadas por estes (algumas vezes de forma drástica), ocasionando a resistência entre os profissionais da área comercial no que se refere à introdução do ECR. Os principais dados sobre a implementação do ECR nas empresas pesquisadas podem ser visualizados no Quadro 4.

\section{Quadro 4: Implementação do ECR}

\begin{tabular}{|c|c|c|c|}
\hline & INDÚSTRIAS & ATACADISTAS & VAREJISTAS \\
\hline $\begin{array}{l}\text { Motivos que } \\
\text { levaram as } \\
\text { empresas a } \\
\text { investirem no } \\
\text { ECR }\end{array}$ & $\begin{array}{l}\text { reduzir custos e a falta de } \\
\text { produtos } \\
\text { melhorar o mix de produtos e o } \\
\text { conhecimento sobre os } \\
\text { consumidores } \\
\text { melhorar a eficiência logística } \\
\text { e a capacidade de expedição de } \\
\text { mercadorias } \\
\text { acompanhar o mercado em } \\
\text { termos de ferramentas e } \\
\text { tecnologias }\end{array}$ & $\begin{array}{l}\text { ganhar eficiência para } \\
\text { evitar a falta de } \\
\text { produtos } \\
\text { reduzir excesso de } \\
\text { estoques } \\
\text { conhecer o } \\
\text { funcionamento do } \\
\text { ECR }\end{array}$ & $\begin{array}{c}\text { ganhar eficiência na gestão de } \\
\text { estoques } \\
\text { aperfeiçoar o mix de produtos } \\
\text { nas lojas } \\
\text { melhorar o relacionamento com } \\
\text { os fornecedores } \\
\text { melhorar o serviço junto aos } \\
\text { fornecedores no que tange à } \\
\text { padronização das cargas e } \\
\text { redução de custos }\end{array}$ \\
\hline Início do ECR & 1996 e 1997 & 1994 e 1998 & 1999 e 2000 \\
\hline $\begin{array}{l}\text { Adoção inicial de } \\
\text { projetos-piloto e } \\
\text { participação do } \\
\text { ECR Brasil }\end{array}$ & $\begin{array}{l}\text { Apenas uma das empresas não } \\
\text { adotou inicialmente projetos- } \\
\text { piloto e contou com a } \\
\text { participação do ECR Brasil }\end{array}$ & $\begin{array}{c}\text { Ambos adotaram } \\
\text { inicialmente projetos- } \\
\text { piloto e apenas um } \\
\text { deles não contou com } \\
\text { a participação do ECR } \\
\text { Brasil }\end{array}$ & $\begin{array}{l}\text { Apenas um dos varejistas adotou } \\
\text { inicialmente projetos-piloto e } \\
\text { contou com a participação do } \\
\text { ECR Brasil }\end{array}$ \\
\hline $\begin{array}{l}\text { Receptividade do } \\
\text { ECR na empresa }\end{array}$ & $\begin{array}{l}\text { diretores e gerentes: boa; } \\
\text { funcionários: boa, mas houve } \\
\text { resistência do pessoal de } \\
\text { vendas }\end{array}$ & $\begin{array}{l}\text { diretores: muito boa; } \\
\text { gerentes: boa, mas } \\
\text { queriam ver primeiro } \\
\text { os resultados; } \\
\text { funcionários: boa }\end{array}$ & $\begin{array}{l}\text { diretores e gerentes: boa; } \\
\text { funcionários: pouco } \\
\text { envolvimento e conhecimento } \\
\text { sobre o ECR }\end{array}$ \\
\hline $\begin{array}{c}\text { Maiores } \\
\text { investimentos } \\
\text { para a } \\
\text { implementar o } \\
\text { ECR }\end{array}$ & $\begin{array}{l}\text { estrutura, desenvolvimento de } \\
\text { programas (aprox. R\$ } 662 \text { mil) }\end{array}$ & $\begin{array}{l}\text { desenvolvimento de } \\
\text { sistemas }\end{array}$ & $\begin{array}{l}\text { investimentos em sistemas } \\
\text { (aprox. R\$ } 15 \text { milhões) }\end{array}$ \\
\hline
\end{tabular}

Fonte: entrevistas realizadas.

\section{Expectativas, Ganhos e Dificuldades na Implementação do ECR}

$\mathrm{Na}$ opinião da maioria dos entrevistados, as empresas de grande porte encontravam-se mais organizadas em termos de estrutura e sistemas para a implementação do ECR, principalmente as grandes indústrias. Considerando os três grupos analisados, os entrevistados consideravam os atacadistas os menos preparados e, consequentemente, estes foram os que menos se envolveram em projetos-piloto. Embora a falta de estrutura tenha sido apontada como um dos obstáculos da inserção dos atacadistas, vale ressaltar que o atacado acabava muitas vezes tendo que amortizar as ineficiências da indústria (produção e entrega de mercadorias), assumindo funções que poderiam ser canalizadas para o ECR. O Quadro 5 explora dados sobre as expectativas, ganhos e dificuldades na implementação do ECR. 


\section{Quadro 5: Expectativas, Dificuldades e Ganhos na Implementação do ECR - Parte A}

\begin{tabular}{|c|c|c|c|}
\hline & INDÚSTRIAS & ATACADISTAS & $\begin{array}{l}\text { VAREJISTAS } \\
\end{array}$ \\
\hline Expectativas & 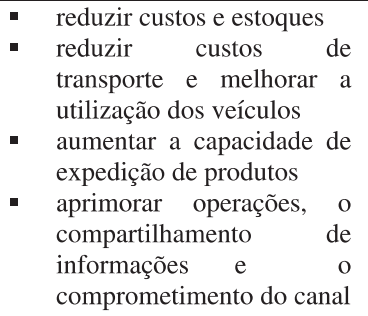 & $\begin{array}{l}\text { ser mais eficiente na } \\
\text { gestão de estoques e } \\
\text { reposição de mercadorias }\end{array}$ & $\begin{array}{l}\text { - melhorar o mix de } \\
\text { produtos de acordo } \\
\text { com as necessidades } \\
\text { dos consumidores } \\
\text { melhorar a gestão de } \\
\text { estoques } \\
\text { melhorar } \\
\text { relacionamento com } \\
\text { os fornecedores }\end{array}$ \\
\hline $\begin{array}{l}\text { Resultados X } \\
\text { Expectativas }\end{array}$ & $\begin{array}{l}\text { os objetivos foram } \\
\text { contemplados, mas vale } \\
\text { lembrar que os resultados } \\
\text { são a longo prazo e ainda } \\
\text { existem outros benefícios } \\
\text { que podem ser alcançados }\end{array}$ & $\begin{array}{l}\text { respostas divergentes; para } \\
\text { um dos atacadistas os } \\
\text { objetivos iniciais foram } \\
\text { contemplados, para o outro } \\
\text { não - indústria não estava } \\
\text { comercialmente preparada } \\
\text { para colocar o ECR em } \\
\text { prática com os atacadistas }\end{array}$ & 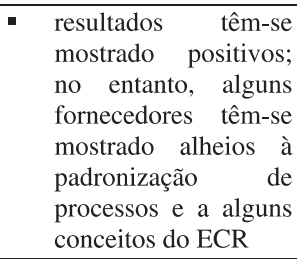 \\
\hline $\begin{array}{l}\text { Principais } \\
\text { dificuldades } \\
\text { internas }\end{array}$ & $\begin{array}{l}\text { - } \begin{array}{l}\text { resistência dos vendedores } \\
\text { (cultural) } \\
\text { falta de conhecimento dos } \\
\text { profissionais da empresa } \\
\text { sobre a operacionalização } \\
\text { do ECR } \\
\text { resistência da área de } \\
\text { informática (outras } \\
\text { prioridades) } \\
\text { comprometimento dos } \\
\text { membros da empresa } \\
\text { falta de confiança entre os } \\
\text { parceiros (compartilhar } \\
\text { dados e trabalhar em }\end{array}\end{array}$ & $\begin{array}{l}\text { - "vender a idéia" para a } \\
\text { área comercial } \\
\text { receio dos gerentes de loja } \\
\text { em perder oportunidades e } \\
\text { poder na negociação com } \\
\text { os fornecedores } \\
\text { barreiras culturais e } \\
\text { resistência às mudanças } \\
\text { sistemas inadequados } \\
\text { - } \\
\text { carência de uma cultura } \\
\text { voltada às inovações } \\
\text { gerenciais }\end{array}$ & 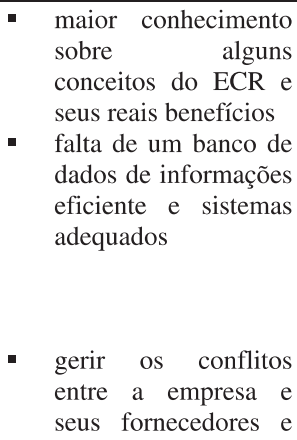 \\
\hline $\begin{array}{l}\text { Principais } \\
\text { dificuldades } \\
\text { externas }\end{array}$ & $\begin{array}{l}\text { conjunto) } \\
\text { carência de uma cultura } \\
\text { voltada às inovações } \\
\text { gerenciais } \\
\text { falta de padronização de } \\
\text { alguns processos e } \\
\text { inadequação dos sistemas } \\
\text { dos clientes } \\
\text { predominância de uma } \\
\text { negociação "ganha-perde" }\end{array}$ & $\begin{array}{l}\text { - integração entre empresas } \\
\text { (relações comerciais) } \\
\text { - gerir informações em } \\
\text { conjunto } \\
\text { inadequação dos sistemas } \\
\text { dos fornecedores } \\
\text { falta de conhecimento dos } \\
\text { fornecedores }\end{array}$ & $\begin{array}{l}\text { padronizar as } \\
\text { operações } \\
\text { definir o papel de } \\
\text { cada um dentro do } \\
\text { conceito do ECR } \\
\text { o fornecedor ainda } \\
\text { precisa avançar nos } \\
\text { conceitos que tangem } \\
\text { o ECR } \\
\text { falta de conhecimento } \\
\text { dos fornecedores }\end{array}$ \\
\hline $\begin{array}{l}\text { Principais } \\
\text { motivos que } \\
\text { acreditam } \\
\text { impedir seus } \\
\text { fornecedores/ } \\
\text { clientes de } \\
\text { investirem no } \\
\text { ECR }\end{array}$ & $\begin{array}{l}\text { - falta de informação e } \\
\text { conhecimento dos reais } \\
\text { benefícios } \\
\text { - barreiras culturais } \\
\text { - carência de investimentos } \\
\text { em sistemas para o } \\
\text { tratamento das } \\
\text { informações } \\
\text { restrições tecnológicas }\end{array}$ & 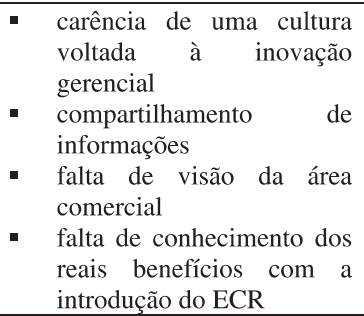 & 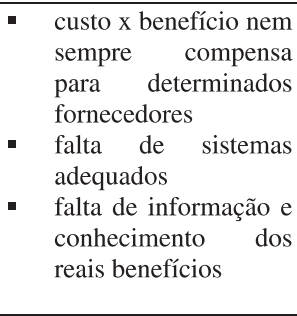 \\
\hline
\end{tabular}




\section{Quadro 5: Expectativas, Dificuldades e Ganhos na Implementação do ECR - Parte B}

\begin{tabular}{|c|c|c|c|}
\hline $\begin{array}{l}\text { Opinião sobre } \\
\text { o preparo das } \\
\text { empresas do } \\
\text { canal para } \\
\text { uma nova } \\
\text { estratégia de } \\
\text { gestão como o } \\
\text { ECR }\end{array}$ & $\begin{array}{l}\text { - as respostas divergentes; } \\
\text { mas a maioria achava que, } \\
\text { de maneira geral, as } \\
\text { indústrias, atacadistas e } \\
\text { varejistas ainda não } \\
\text { estavam preparados para o } \\
\text { ECR }\end{array}$ & $\begin{array}{l}\text { - as grandes indústrias } \\
\text { nacionais e as } \\
\text { multinacionais estavam } \\
\text { mais preparadas para o } \\
\text { ECR } \\
\text { pouca participação dos } \\
\text { atacadistas, pois não } \\
\text { estavam muito } \\
\text { preparados }\end{array}$ & $\begin{array}{l}\text { - as empresas maiores } \\
\text { estavam preparadas, mas } \\
\text { queriam ver resultados } \\
\text { satisfatórios antes de } \\
\text { implementarem o ECR; } \\
\text { as de menor porte ainda } \\
\text { não estavam preparadas } \\
\text { para o ECR }\end{array}$ \\
\hline $\begin{array}{c}\text { Principais } \\
\text { ganhos obtidos } \\
\text { com a } \\
\text { implementação } \\
\text { do ECR }\end{array}$ & $\begin{array}{l}\text { - } \begin{array}{l}\text { redução de estoques, } \\
\text { ruptura de produtos e } \\
\text { custos } \\
\text { distribuição mais linear de } \\
\text { produtos } \\
\text { agilidade na entrega de } \\
\text { produtos manuseio interno } \\
\text { de mercadorias } \\
\text { maior agilidade nos } \\
\text { pedidos } \\
\text { maior conhecimento das } \\
\text { lojas, clientes e mercado }\end{array} \\
\text { - }\end{array}$ & 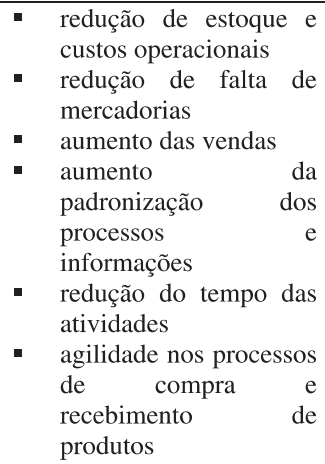 & $\begin{array}{l}\text { maior conhecimento } \\
\text { sobre o desempenho dos } \\
\text { produtos nas lojas } \\
\text { melhor fluxo de } \\
\text { informações } \\
\text { empresas (no tempo } \\
\text { adequado) } \\
\text { melhor gestão do estoque }\end{array}$ \\
\hline $\begin{array}{c}\text { Fornecedores/ } \\
\text { clientes aptos } \\
\text { a } \\
\text { desenvolvere } \\
\text { m as } \\
\text { estratégias do } \\
\text { ECR }\end{array}$ & $\begin{array}{l}\text { - das } 4 \text { indústrias, } 3 \\
\text { afirmaram que os seus } \\
\text { clientes, responsáveis por } \\
70 \% \text { do volume total } \\
\text { vendido em dinheiro, } \\
\text { estavam aptos ao ECR }\end{array}$ & $\begin{array}{l}\text { seus fornecedores, } \\
\text { responsáveis por } 70 \% \\
\text { do volume total em } \$ \\
\text { em compras, estavam } \\
\text { aptos ao ECR }\end{array}$ & $\begin{array}{l}\text { seus fornecedores, } \\
\text { responsáveis por } 65 \% \text { do } \\
\text { volume total em } \$ \text { em } \\
\text { compras, estavam aptos } \\
\text { ao ECR }\end{array}$ \\
\hline
\end{tabular}

Fonte: entrevistas realizadas.

\section{Adoção das Estratégias, Processos, Tecnologias e Métodos do ECR}

\section{A Reposição Eficiente de Produtos}

Devido às as barreiras culturais e tecnológicas existentes para a implementação da Reposição Eficiente de Produtos, sua maior difusão no Brasil, na visão dos entrevistados, deve acontecer a médio prazo nas empresas de grande porte e a longo prazo nas de médio e pequeno porte. Esses dados podem ser visualizados no Quadro 6. 


\section{Quadro 6: Adoção da Reposição Eficiente de Produtos}

\begin{tabular}{|c|c|c|c|}
\hline $\begin{array}{c}\text { Reposição Eficiente } \\
\text { de Produtos }\end{array}$ & INDÚSTRIAS & ATACADISTAS & VAREJISTAS \\
\hline $\begin{array}{c}\text { Empresas em } \\
\text { operação }\end{array}$ & 2 & 1 & 1 \\
\hline Ano de implantação & 1995 e 2000 & 1996 & 1998 \\
\hline $\begin{array}{l}\mathrm{N}^{\circ} \text { de fornecedores } \\
\text { em operação }\end{array}$ & Entre 25 a 32 clientes & 25 fornecedores & 680 fornecedores \\
\hline $\begin{array}{l}\text { Expectativas } \mathrm{X} \\
\text { realizado }\end{array}$ & $\begin{array}{l}\text { aumentar a capacidade de } \\
\text { expedição de produtos e } \\
\text { redução de custos }\end{array}$ & $\begin{array}{l}\text { - manter os níveis de } \\
\text { estoque de acordo } \\
\text { com a demanda }\end{array}$ & $\begin{array}{ll}\text { - reduzir falta de } \\
\text { produtos } & \text { e agilizar } \\
\text { os } & \text { processos } \\
\text { internos } & \\
\end{array}$ \\
\hline Ganhos obtidos & $\begin{array}{l}\text { - } \quad \text { redução do estoque e ruptura } \\
\text { de produtos nas lojas } \\
\text { - } \quad \text { demmento do nível de serviço } \\
\text { - maior conhecimento sobre os } \\
\text { produtos nas lojas }\end{array}$ & $\begin{array}{l}\text { - } \quad \text { aumento das vendas } \\
\text { produção da falta de } \\
\text { produtos }\end{array}$ & 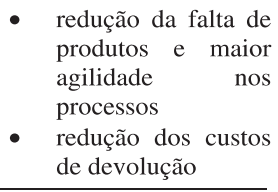 \\
\hline Obstáculos & $\begin{array}{ll} & \text { barreiras culturais: } \\
\text { compartilhar informações } \\
\text { estrutura interna, caso muitos } \\
\text { se interessem (via VMI) }\end{array}$ & $\begin{array}{ll}\text { - } & \text { adequação do } \\
\text { sistema } & \text { gerenciamento das } \\
\text { informações }\end{array}$ & $\begin{array}{l}\text { - barreiras culturais } \\
\text { (novas formas de } \\
\text { negócios entre } \\
\text { empresas) }\end{array}$ \\
\hline $\begin{array}{l}\text { Mudanças } \\
\text { necessárias }\end{array}$ & $\begin{array}{l}\text { - capacitação de sistemas e } \\
\text { processos logísticos (área } \\
\text { armazenagem e expedição, } \\
\text { padronização de caminhões, } \\
\text { paletização) }\end{array}$ & $\begin{array}{ll}\text { - } & \text { sistema de } \\
\text { informação } \\
\text { - } \\
\text { - } \\
\text { treinamanantonto culturais } \\
\end{array}$ & $\begin{array}{lr}\text { - } & \text { maior abertura para } \\
\text { as lojas } & \text { poderem } \\
\text { gerenciar } & \text { as } \\
\text { quantidades } & \text { de } \\
\text { produtos } & \\
\end{array}$ \\
\hline $\begin{array}{l}\text { Investimentos } \\
\text { necessários }\end{array}$ & $\begin{array}{l}\text { sistemas e processos internos } \\
\text { (logística) }\end{array}$ & $\begin{array}{lr}\text { - } & \begin{array}{l}\text { treinamento } \\
\text { adequação } \\
\text { sistemas }\end{array} \\
\end{array}$ & - sistemas \\
\hline $\begin{array}{l}\text { Previsão de } \\
\text { expansão do } \mathrm{n}^{\circ} \mathrm{de} \\
\text { forn./clientes com os } \\
\text { quais realizam a } \\
\text { Reposição Eficiente } \\
\end{array}$ & $\begin{array}{l}\text { pretende ampliar (curto e } \\
\text { médio prazo), mas é } \\
\text { fundamental que os clientes } \\
\text { estejam mais preparados }\end{array}$ & $\begin{array}{l}\text { pretende ampliar, a } \\
\text { curto e médio prazo }\end{array}$ & $\begin{array}{l}\text { - pretende ampliar, a } \\
\text { curto e médio prazo }\end{array}$ \\
\hline
\end{tabular}

Fonte: entrevistas realizadas.

Algumas empresas que já se encontram mais evoluídas no desenvolvimento de processos de reposição mais eficientes, têm adaptado este desenvolvimento aos diferentes produtos comercializados. Algumas especificidades usualmente consideradas são o grau de perecibilidade e a passagem ou não pelo centro de distribuição da indústria ou do varejista. Em alguns dos casos estudados, a escolha pelo tipo de reposição a ser adotado, no caso do varejistas é realizada internamente e não em comum acordo com seus fornecedores. O objetivo é definir a melhor opção, considerando as estratégias definidas para cada categoria de produtos.

As empresas pesquisadas não divulgaram os investimentos necessários para a viabilização dessa estratégia. Inicialmente começaram adotando projetos-piloto, que eram avaliados mensalmente, e que contavam, algumas vezes, com o apoio de consultorias especializadas e a Associação ECR Brasil. Devido aos resultados positivos, novos projetos foram iniciados com outras organizações. Os benefícios 
eram claros, resultando no comprometimento dos profissionais envolvidos, que buscavam maximizar tais ganhos.

\section{Sortimento Eficiente de Produtos}

A estratégia Sortimento Eficiente de Produtos foi encontrada em apenas uma das indústrias estudadas. Atualmente diversos projetos estão em testes, embora apenas com dois clientes o Sortimento Eficiente de Produtos esteja efetivamente sendo operacionalizado. A expectativa da indústria era ampliar sua participação de mercado, através do melhor gerenciamento das linhas de produtos e ela foi contemplada. A indústria começou trabalhando com apenas uma categoria de produtos na rede varejista (esta não faz parte da amostra) e depois foi ampliando esse número (segundo os entrevistados, na maioria das vezes é assim que esse processo também ocorre nas demais instituições). A escolha de qual categoria seria trabalhada foi simples: a empresa escolheu aquela em que tinha pouca participação de mercado, sendo esta inferior do que considerava justa. Havia, portanto, a possibilidade de um ganho potencial a ser trabalhado.

No entanto, segundo alguns dos entrevistados, o Sortimento Eficiente de Produtos pode ser considerado uma estratégia complexa, já que requer altos investimentos em softwares e ainda há o problema da incompatibilidade entre os sistemas das empresas (interface). Para a operacionalização dessa estratégia as empresas precisam adquirir um software para analisar as informações sobre as lojas e sobre a categoria de produtos, tais como: dados sobre todos os produtos da categoria analisada, preços, tamanho das embalagens, posicionamento das embalagens (algumas embalagens são colocadas na vertical, outras na horizontal), informações sobre o espaço nas gôndolas, tamanho das gôndolas, e isso é feito loja a loja, já que as informações diferem de uma empresa para outra. Todas estas informações são trabalhadas e analisadas por esse software, para se chegar à melhor definição do sortimento - quais produtos deverão estar nas gôndolas, em quais posições e por quais preços.

Na opinião dos entrevistados da empresa que desenvolve o Sortimento Eficiente de Produtos, as entidades de menor porte não têm atualmente condições de investirem em um software sofisticado desse tipo. A tendência é que aos poucos o fluxo de informações migre para a Internet e torne essa operação mais barata. Eles acreditam que a difusão do Sortimento Eficiente de Produtos ocorrerá no longo prazo no Brasil.

\section{A Promoção Eficiente de Produtos}

Das empresas pesquisadas, duas indústrias realizavam a Promoção Eficiente 
de Produtos e esta estratégia foi implementada entre os anos de 2000 e 2001. Apenas uma delas adotou inicialmente um projeto-piloto e nenhuma das duas contaram com o envolvimento do ECR Brasil ou de uma consultoria. Para melhor compreensão da operacionalização dessa estratégia, considerou-se relevante separar os dois casos estudados.

Na indústria X (empresa multinacional, de grande porte), a Promoção Eficiente de Produtos foi implementada pela primeira vez em 2001. Esta estratégia pode ser compreendida em duas etapas: $\mathbf{1}^{\mathbf{a}}$ Etapa: a indústria, em conjunto com o seu cliente (varejista, atacadista ou distribuidor), faz um planejamento das promoções que serão realizadas em um período pre-determinado. Nesse momento, são definidas metas únicas para os produtos da empresa nas lojas desse cliente, sendo elas estabelecidas em conjunto. Tem-se então uma programação das promoções, metas e objetivos bem definidos para cada linha de produto. Esse processo está sendo feito hoje na empresa com todos os seus distribuidores e com quatro varejistas de grande porte. $2^{\mathbf{a}}$ Etapa: consiste na avaliação dos efeitos das promoções. A indústria $\mathrm{X}$ avalia todas as promoções realizadas nas lojas de seus clientes, e não apenas naquelas que participaram do planejamento e definição de metas. Nessa etapa, a indústria não apenas analisa o efeito da Promoção Eficiente de Produtos, como também o impacto da Introdução de Novos Produtos. Nesse sentido, a empresa considera a Promoção e a Introdução Eficiente de Produtos duas estratégias bastante relacionadas entre si e que, portanto, devem ser avaliadas em conjunto.

Na indústria Y (empresa multinacional, de grande porte), a implementação da Promoção Eficiente de Produtos ocorreu em 2000 e foi consolidada na empresa por meio da definição de um calendário de promoções em conjunto com os parceiros comerciais. Atualmente a empresa está desenvolvendo esta estratégia com 6 grandes clientes, que representam 15\% das vendas da empresa. A adoção dessa estratégia foi uma forma encontrada pela indústria Y para reduzir a complexidade das promoções, que acabaram assumindo custos muito elevados e dificultando a programação da produção da empresa. Após a definição do calendário das promoções, a empresa passou a planejar melhor sua produção e conseguiu reduzir os custos dos esforços promocionais.

Dentre os principais ganhos obtidos pelas duas indústrias destacam-se: redução da ruptura de produtos, já que o planejamento em conjunto permitiu que a indústria se programasse melhor para atender os picos de demanda nos períodos de promoção; aumento das vendas; e redução das despesas, por meio de melhor alocação dos recursos destinados às promoções. Das principais dificuldades enfrentadas na implementação da Promoção Eficiente de Produtos destacam-se as barreiras culturais. Para a realização dessa estratégia, torna-se fundamental 
o trabalho conjunto entre as empresas, que algumas vezes ainda resistem em mudar sua forma de trabalho, focada nos interesses individuais.

A previsão das empresas é a ampliação dessa estratégia para os distribuidores e para alguns varejistas. De acordo com os entrevistados, existe apenas uma empresa no Brasil que está atualmente fazendo a Promoção Eficiente de Produtos de maneira correta.

\section{A Introdução Eficiente de Produtos}

Segundo os entrevistados, a Introdução Eficiente de Produtos é a estratégia do ECR menos empregada pelas empresas no Brasil. Dentre as empresas pesquisadas que ainda não a implementaram, a grande maioria não mostrou muito interesse, seja a curto, médio ou longo prazo. Apenas uma das indústrias pesquisadas estava realizando essa estratégia.

De acordo com a bibliografia estudada, a Introdução Eficiente de Produtos é a estratégia do ECR que menos proporciona a redução significativa de custos (apenas $0,9 \%$ no preço final do produto). Os benefícios são dificilmente mensuráveis, a relação de trabalho necessária entre as indústrias e seus parceiros é extremamente complexa, sendo considerada por muitas empresas uma estratégia utópica, difícil de ser colocada em operação. Sendo assim, a difusão dessa estratégia nas empresas brasileiras pode ser considerada limitada.

Considerando os principais ganhos percebidos pela indústria com a adoção dessa estratégia, destacam-se: maiores vendas e melhor definição do mix de produtos. Dentre os principais obstáculos citados pelos entrevistados, têm-se as barreiras culturais, já que para a operacionalização dessa estratégia se torna fundamental o estabelecimento de novas formas de trabalho, realizadas em conjunto entre os departamentos das empresas.

Atualmente a indústria pesquisada que já desenvolve essa estratégia (multinacional), está realizando a Introdução Eficiente de Produtos com 24 clientes, sendo 20 distribuidores e quatro varejistas. Essa estratégia implica o planejamento e definição de metas em conjunto. De acordo com os entrevistados, a Introdução Eficiente de Produtos foi implementada efetivamente na empresa no ano de 2001 (juntamente com a Promoção Eficiente de Produtos) e não contou com o envolvimento do ECR Brasil e de nenhuma consultoria. 


\section{Considerações Finais}

De acordo com o estudo realizado, percebe-se que as indústrias multinacionais foram as pioneiras na introdução das estratégias do ECR (transferência de conhecimento e experiências no mercado externo) e o maior envolvimento do varejo aconteceu recentemente, na medida em que esses se conscientizaram da necessidade do ECR para o ganho de eficiência nas operações de negócios. Observou-se também que as indústrias, de maneira geral, estão mais preparadas no que tange à infra-estrutura e cultura necessária para a viabilização do ECR e se mostram mais motivadas e comprometidas em investir recursos e tempo na implementação dessa estratégia de gestão.

Pode-se dizer que o ECR nada mais é do que uma estratégia de gestão que envolve diversos conceitos de eficiência de negócios introduzidos anteriormente, no que tange à redução de custos e estoques e ganho de eficiência nas operações no canal de distribuição. No entanto, embora a teoria do ECR enfatize o consumidor como sendo o elemento fundamental dos esforços das empresas, percebe-se que na prática ainda existe forte tendência das mesmas em focar na redução de custos.

Com base na pesquisa empírica, pode-se afirmar que um dos maiores benefícios obtidos com a introdução do ECR foi o ganho em eficiência na reposição de produtos, o que possibilitou reduzir, principalmente, estoques e custos operacionais. Mesmo que a introdução dessa estratégia esteja em um estágio incipiente nas empresas pesquisadas, pôde-se perceber o interesse e esforço da maioria dessas instituições em ampliarem o número de parceiros com os quais realizam essa estratégia, visando à maximização dos ganhos.

Os resultados obtidos na pesquisa de campo mostram que ainda existe uma série de dificuldades para a maior disseminação do ECR, como: resistência por parte das empresas em trocar informações, o relacionamento existente é focado nos interesses individuais e a maior satisfação do consumidor é vista como uma consequiência da eficiência das operações de negócio e não tida como um objetivo primordial dos esforços despendidos. É necessário que as empresas reavaliem suas metas com a implementação do ECR e o papel de cada parceiro nas ações conjuntas entre empresas.

No entanto pôde-se perceber que existe o interesse das empresas em expandir os projetos de ECR. Aos poucos essas estão se conscientizando da necessidade de ganhar eficiência e competitividade e o ECR é uma estratégia de gestão focada nesses ganhos. Sendo assim, pode-se dizer que o ECR vem ganhando 
espaço e as empresas se têm mostrado cada vez mais interessadas em estar ao menos tentando entender os conceitos que permeiam o ECR. Isso significa que sua maior difusão provavelmente acontecerá a longo prazo. Mesmo que novas ferramentas e tecnologias surjam nesse percurso, o ECR terá dado sua contribuição.

\section{Artigo recebido em 27.05.2004. Aprovado em 23.11.2004.}

\section{REFERÊNCIAS BibLIOGRÁfICAS}

Alcântara, R. L. C. (1999, dezembro). Sistemas de distribuição e arranjos cooperativos: o caso do atacado brasileiro. Gestão \& Produção, 6(3), 219-232.

Brockman, B. K., \&

Morgan, R. M. (1999, October/ November).

The evolution of managerial innovations in distribution: what prospects for ECR? International Journal of Retail \& Distribution Management, 27(10), 20-43.

Ching, H. Y. (1999).

Gestão de estoques na cadeia de logística integrada: supply chain. São Paulo: Atlas.

Clark, T. H., \&

Croson, D. H. E. (1997).

Butt grocery company: a leader in ECR implementation. Harvard Business School. Recuperado em 10 junho, 2001, de http:// www.mjs.cmich.edu/mba609_s2k/ disc3_tocif.htm

De Roulet, D. G. (1993, October).

ECR: better information cuts costs. Transportation \& Distribution, 34(10), 63-70.
Dib, J. A. (1997, abril/junho).

Efficient Consumer Response (ECR): uma estratégia para o varejo de bens de consumo de massa. Revista de Administração da USP, 32(2), 14-22.

ECR Brasil (1998).

ECR Brasil visão geral: potencial de redução de custos e otimização de processos. Coleção ECR Brasil. São Paulo: Associação ECR Brasil.

Fleury, F. P.,

Wanke, P., \&

Figueiredo, K. F. (Orgs.). (2000).

Logística empresarial: a perspectiva brasileira. São Paulo: Atlas.

Fox, B. (1992, March).

Battle of grocery formats Intensifies: vendors under pressure to choose sides. Chain Store Age Executive, 68(5), 48.

Garry, M. (1992, June).

Dealing with the mass merchants. Progressive Grocer, 71(6), 73-78.

Garry, M. (1994, July).

How to stop the beeding. Progressive Grocer, 73(7), 85-88. 
Garry, M. (1995, January).

Industry snap shot. Progressive Grocer, 74(1), 11.

Ghisi, F. A. (2000).

Os indicadores de desempenho na avaliação do ECR no médio varejo. Menção Honrosa recebida no I Prêmio ECR de Pesquisa, dentre os três melhores trabalhos. (trabalho não publicado).

Ghisi, F. A. (2001).

A implementação do ECR (Efficient Consumer Response) no canal de distribuição de produtos de mercearia básica: um estudo multicaso. Dissertação de Mestrado, Universidade Federal de São Carlos, SP, Brasil.

Harris, J. K., \&

Swatman, P. M. C. (1997).

Efficient consumer response (ECR) in Australia: the Australian grocery industry in 1996. Anais Pacific Asia Conference On Information Systems, Brisbane, Queensland, 3, 427-440.

Harris, J. K.,

Swat.Man, P. M. C., \&

Kurnia, S. (1999, January).

Efficient consumer response (ECR): a survey of the Australian grocery industry. Supply Chain Management, 4(1), 137-148.

Hoffman, J. M., \&

Mehra, S. (2000, February).

Efficient consumer response as a supply chain strategy for grocery businesses, International Journal of Service, 11(4), 365-373.
King, R. P.,

Ashman, S. M., \&

Bosley, S. A. (1994).

Store-level innovation in the retail food industry: the ECR initiative and beyond. Anais Joint Conference on Food, Agriculture and Environment, Minneapolis, Minnesota, 6.

Kotzab, H. (1999, May).

Improving supply chain performance by efficient consumer response? A critical comparison of existing ECR approaches. The Journal of Business \& Industrial Marketing, 14(5/6), 364-377.

Kurnia, S.,

Swatman, P. M. C., \&

Schauder, D. (1998).

Efficient Consumer Response: a preliminary comparison of US and European experiences. Proceddings The International Bled Electronic Commerce Conference, Bled, Slovenia, 11, 126-143.

Kurt Salmon Associates (1993).

Efficient Consumer Response: enhancing consumer value in the grocery industry. Food Marketing Institute, Washington, D.C.

Newton, D. J. (1993, Mach/August).

Nontraditional retailers challenge the supermarket industry. Food Review, 16(1), 2-7.

O’Neill, R. E. (1992, May).

Close-up clubs. Progressive Grocer, 71(5), 61-78. 
Pearce, A. M. (1996, February).

Efficient consumer response: managing the supply chain for "ultimate" consumer satisfaction. Supply Chain Management, 1(2), 4552.

Phumpiu, P. F., \&

King, R. P. (1997, February).

Adoption of ECR practices in Minnesota grocery stores. The Retail Food Industry Center. Advancing Knowledge About Processing, Distribution, Sales and Food Service, 32(97-01).

Poirier, C. C., \&

Reiter, S. E. (1996).

Supply Chain Optimization. São Francisco: Berret-Koehter.

Rojo, F. J. C. (1998).

Supermercados no Brasil: qualidade total, marketing de serviços, comportamento do consumidor. São Paulo: Atlas.

Ross, J. R. A. (1996, May).

Retailers take the lead in implementing ECR. Stores, 78(5), 30-33.

Sansolo, M. (1993, November).

ECR. Progressive Grocer, 72(11), 4650.

Selltiz, C., \&

Cook, S. W. (1974).

Métodos de pesquisa nas relações sociais. São Paulo: EPU.
Silva, A. L. (1999).

A adoção de tecnologia de informação em canais de distribuição: um estudo multicaso na utilização de EDI entre o varejo e industria agroalimentar. Tese de Doutorado, Faculdade de Economia, Administração e Contabilidade. Universidade de São Paulo, SP, Brasil.

Silveira, G. J. A., \&

Lepsch, S. L. (1997, abril/junho).

Alterações recentes na economia do setor supermercadista brasileiro. Revista de Administração da USP, 32(2), 5-13.

Vantine, J. G. (1998, August).

Efficient consumer response. Revista Saperspectiva, (6-8), pp. 38-43.

Vilallonga, M. (1996).

El año de la repuesta eficiente al consumidor. Recuperado em 5 janeiro, 1999, de http:// www.aecoc.es

Whipple J. S., Frankel R., \&

Anselmi K. (1999, April).

The effect of governance structure on performance: a case study of efficient consumer response. Journal of Business Logistics, 20(2), 43-61.

Yin, R. K. (1994).

Case study research: design and methods (2nd ed.). Thousand Oaks: SAGE publications. 